\title{
Relações entre expressão e conteúdo na poesia concreta
}

\author{
Juliana Di Fiori PONDIAN (USP)
}

RESUMO: a partir da análise do poema "lygia fingers", de Augusto de Campos, pretendemos depreender algumas características da poesia concreta, e verificar como se dão as relações entre o plano da expressão e o plano do conteúdo nesse tipo de discurso, dado que a poesia concreta trabalha com a máxima exploração do plano de expressão.

PALAVRAS-CHAVE: semiótica; poesia concreta; plano da expressão; semisimbolismo.

RESUMÉ: Afin de cerner quelques traits typiques de la poésie dite concrète, on propose ici une analyse d'un poème d'Augusto de Campos, intitulé "lygia fingers" (poetamenos, 1955). La poésie concrète exploitant au maximum les ressources du plan de l'expression, nous partous une attention particulière aus rapports signifiant/signifié dans ce genre de texte.

MOTS-CLÉS: sémiotique; poésie concrète; plan de l'expression ; semi-symbolism. 
A poesia concreta brasileira surge às voltas de 1950, com um discurso contrário ao dos poetas representativos daquele tempo, a Geração de 45. Em linhas gerais, o projeto do grupo Noigandres (em princípio, Décio Pignatari, Augusto de Campos e Haroldo de Campos - mentores do movimento) consistia em instaurar no cenário poético brasileiro/mundial uma nova poesia, com base nos trabalhos de alguns poetas anteriores, eleitos por meio de um resgate-peneira da tradição.

Essa "nova poesia" tinha entre suas principais intenções aproximar-se da música e das artes visuais, produzindo, ao fim, um texto "verbivocovisual" - palavravalise criada por James Joyce, e amplamente utilizada pelos poetas concretos a fim de definir sua poesia. Assim, o poema agora se constituiria a partir da máxima exploração do plano da expressão da linguagem verbal, em suas características plásticas e sonoras, acrescentando-lhe recursos estritamente visuais, como cores e distribuição da palavra na página.

Se admitirmos essas características como sendo definições estéticas primeiras da poesia concreta brasileira, temos um discurso interessante enquanto objeto de estudo para a semiótica, dado que os fatores mencionados constituem importantes fenômenos para a teoria. Vejamos quais são eles.

Por um lado, essa "verbivocovisualidade" resulta, do ponto de vista semiótico, em um texto sincrético, o que constitui hoje um fenômeno dos mais controversos entre os semioticistas, e que não abordaremos aqui. Por outro lado, a exploração do plano da expressão exige uma descrição à altura, e ainda não dispomos de um modelo bem consolidado para o estudo do plano da expressão tal qual o temos para o plano do conteúdo, que, no texto em questão, também se mostra diferente.

No poema concreto, a matriz sujeito-predicado, unidade mínima do discurso utilitário cotidiano, é substituída por uma "sintaxe espacial", onde os termos se associam segundo "operações semânticas" próprias, formando blocos de significação que exigem do leitor um esforço em concatená-los.

Desse modo, essas seriam as principais características do plano da expressão e do plano do conteúdo da poesia concreta; no entanto, sabemos que ambos estão unidos por uma relação de dupla pressuposição, a qual também devemos descrever.

Ora, conforme foi dito, se tomarmos como característica primeira da poesia concreta a exploração máxima do significante - ou seja, a exploração do caráter plástico de todo texto escrito, auxiliado pela sua distribuição no espaço da página - notamos que o poeta investe conteúdos no poema além daqueles arbitrários próprios da linguagem verbal. Desse modo, podemos dizer que há uma relação entre as categorias do plano da expressão e as categorias do plano do conteúdo, o que resulta para nós em um efeito de motivação do signo, brincando com a máxima lingüística da arbitrariedade. Assim, podemos pensar que os poetas concretos retomam a característica mais primitiva da 
escrita, que foi, no princípio, pura imagem, e funcionava como uma tentativa de cópia fiel dos seres e entes da realidade, ou seja, onde as "palavras" deveriam, literalmente, representar as "coisas"; característica essa que foi rompida com o passar do tempo e a invenção do alfabeto, desmotivado pictoricamente.

Com o fim de ilustrar as proposições ora colocadas, mostraremos aqui a análise de um poema da série poetamenos (1955), de Augusto de Campos. Nesta série podemos notar a presença de grande parte dessas intenções estéticas do movimento concretista que, na época, estava se formando.

poetamenos é uma série de seis poemas e contém um texto introdutório em que Augusto esboça as premissas que o guiam para escrever os poemas, visando explicar ou, ainda, justificar sua prática poética. No texto, em uma espécie de inspiraçãohomenagem à obra de Anton Webern, diz ele querer construir uma "Klangfarbenmelodie" (melodia de timbres) com palavras, cujos instrumentos seriam a "frase/palavra/sílaba/letra(s)" de modo a construir "temas gráfico-fonéticos ou ideogrâmicos".

A "Klangfarbenmelodie" é um método de composição musical que, criado no início do século XX pelo compositor alemão Arnold Schoenberg, exerceu grande influência na música erudita desde então, se estendendo até a literatura, como podemos perceber. Tal método consiste em aplicar continuamente mudanças de timbre sobre uma mesma nota, acorde ou frase musical; ou seja, a melodia se desenvolve essencialmente por uma mudança de instrumentos (relações de timbre), e não somente por uma combinação de notas (relações de altura).

O poema que escolhemos para análise aqui é chamado "lygia fingers" (anexo número 1). Nesse poema, veremos como o jogo entre as cores-timbres (manipulação do significante) é o que, de fato, constrói a unidade do poema, indicando também transformações no conteúdo. A preocupação visual é evidente, basta ver a composição cromática e a disposição das palavras no branco da página. A preocupação sonora manifesta-se, além das aliterações e assonâncias, quando da realização oral do poema, dado que cada cor deve ser lida por uma voz (timbre) diferente.

"lygia fingers" é o terceiro poema da série poetamenos. Se em toda a série Augusto utiliza seis cores para compor seus poemas, em "lygia fingers" encontramos cinco delas: vermelho, verde, amarelo, azul e roxo, que podem desde já ser divididas em "quentes" e "frias".

O poema começa com a palavra "lygia", ou seja, um substantivo próprio feminino, seguido pelo verbo "finge". Assim, já de início se instaura uma ambigüidade no poema: será "lygia" um vocativo, e o verbo está, consequentemente, no imperativo; ou, será "lygia" simplesmente o sujeito do verbo na terceira pessoa? Somente o 
desenrolar do texto poderia nos ajudar a resolver a ambigüidade, mas não é o que acontece, e as duas leituras parecem possíveis.

Na linha abaixo, encontramos um "rs", duas letras que, sozinhas, não fazem sentido algum em português. Porém, na estrutura relacional do poema, o "rs" deve ser somado ao "finge" da primeira linha, assim formando a palavra "fingers", acrescentando mais uma possibilidade àquela ambigüidade inicial, "lygia fingers".

As linhas seguintes se apresentam como um diálogo do enunciador com seus instrumentos de escrita, além de evocar Lygia: "dedat illa grypho" ecoa em português "datilografo" ou, ainda, "te datilografo". "Lygia, finge ser digital", como se por meio da escrita pudesse presentificá-la. Eduardo Sterzi, num breve comentário sobre a série no artigo intitulado "Todos os sons, sem som" já afirmara esse aspecto, traçando um importante paralelo deste poema com o último da série, "dias dias dias":

“À impressão inicial de que se está ouvindo a voz do poeta entremeada às vozes da amada (...) substitui-se à constatação de que estamos diante de um diálogo do poeta consigo mesmo e com as ferramentas de sua escrita (está redigindo uma carta, que é também o poema).” (STERZI, 2004: 107)

Em uma segunda leitura, não-linear, a frase (sujeito-verbo-predicado) desaparece, dando lugar à formação de "blocos semânticos", por meio da associação de imagens. Assim, as palavras: fingers, digital, dedat e grypho (grifar/grafar) irão compor com lynx, grypho (animal mitológico), felyna e felix, uma isotopia /felina/.

Cabe lembrar que as associações feitas até agora não são somente evocadas pelo significado das palavras, mas também pelos efeitos que advêm da sonoridade delas. Nesse sentido, destacamos dois procedimentos comuns a toda a série acerca da sonoridade, aos quais chamamos: "analogias fônicas" e "isotopias sonoras". Analogias fônicas consistem em uma total exploração da estrutura fônica da palavra, que se torna capaz de evocar (por analogia) sentidos díspares, que nada têm a ver com sua etimologia real. Esse mecanismo está associado também ao plurilingüismo dos poemas, e, além do significado próprio da palavra em sua língua, essa é capaz de produzir ecos em outras (falsos ou verdadeiros cognatos), por meio das analogias fônicas mencionadas. Haroldo de Campos, em artigo sobre Mallarmé, nomeou muito bem essa característica como "efeito de etimologia". Por "isotopias sonoras" entendemos o resultado dos recursos de sonoridade próprios da linguagem poética: aliterações, assonâncias e paronomásias, também amplamente explorados por Augusto. Tais recursos vão tecendo, ao longo dos textos, uma certa redundância sonoro-plástica, que tem papel de destaque na produção da unidade do poema, e da série como um todo.

Desse modo, essa isotopia /felina/ viria para qualificar a mulher (lygia), que está sendo construída no poema. A essa característica “felina”, irão justapor-se outros 
três substantivos, compondo outro bloco semântico para construir o "ideograma" da mulher amada: mãe, figlia e sorella.

Ora, mãe, filha e irmã são as referências primeiras num universo passional que tem por objeto uma figura feminina. Assim, Augusto constrói a figura da mulher (Lygia), qualificando-a com o adjetivo "felina", e então o universo passional descrito sai de um âmbito familiar, por assim dizer, para ganhar uma conotação amoroso-sexual: lygia lynx.

Essa é, portanto, a "personagem" apresentada no poema, Lygia, que identificamos como sendo a "dominante" no texto. O mais interessante, e constitui nosso objetivo demonstrar, é que esse fato pode ser verificado também no plano da expressão, como veremos a seguir, potencializando o "efeito de ubiqüidade" atribuído a Lygia.

Se admitirmos que a palavra "lygia" possui uma identidade visual /cor vermelha/, e uma identidade sonora, o fonema /i/; e, em seguida, verificarmos a ocorrência dessas duas marcas no poema, veremos que tanto uma quanto a outra são predominantes (anexos 2 e 3 ).

A cor vermelha está presente em 10 das 12 linhas do poema, sendo, de longe, nesse aspecto, a cor predominante. $\mathrm{O}$ fonema /i/ também é a vogal que mais aparece no texto. Além disso, as únicas palavras que aparecem "inteiras" e escritas em vermelho são: lygia e lynx, ou seja, o substantivo e seu qualificador, conforme visto acima.

Então, podemos dizer até o momento que o poema trata da construção de um sujeito, Lygia, e que esse sujeito é, de fato, a "dominante" do poema, que se faz presente no conteúdo e na expressão. No entanto, após o isolamento da cor vermelha e do fonema /i/, notamos que existe uma região do poema que essas características não estão presentes (região quadriculada nos anexos 2 e 3).

É nessa mesma região em que há também a formação de um outro "bloco semântico", indicador de um estado de solidão, em que predomina a cor roxa-azul, e o fonema /o/. Indicadores dessa solidão, e de um possível estado disfórico, são os termos e as analogias fônicas: only, lonely, one (l-ONE-ly), sorella (só ela), so (4x, "só"), la sera (lacera).

Assim, fica evidente que ocorre uma transformação de estado no percurso narrativo do sujeito "eu" no poema. Esse sujeito sai da conjunção -eufórica - com seu objeto "lygia" (tratado até aqui como sujeito do ponto de vista do enunciado, agora objeto do ponto de vista do enunciador), para a disjunção - disfórica -, ou, como veremos a seguir, a não-conjunção. 
Chamaremos então, "primeira parte" (região superior, topologicamente), aquela que vai da primeira até a sétima linha. Nesse trecho, temos a predominância das marcas sonora e visual de Lygia, além de termos indicadores de um estado de conjunção (eufórico): lygia (suprimindo um "i" = liga), lynx (links = ligações), com, sim (em grego, syn = com), liame (na sétima linha "figLIA ME”), felix, sim.

A segunda parte (região inferior) vai da oitava até a última linha do poema. É na passagem de uma para a outra que identificamos uma transformação no plano da expressão, acompanhada de uma transformação no conteúdo, e do estado juntivo da relação sujeito-objeto. É esse o trecho em que predomina a solidão e a tristeza decorrente dela, lacera ("LA SERA").

Além disso, se atentarmos somente para o significante "lygia", poderemos acompanhar seu "afastamento" gradualmente. A representação da presença/ausência de Lygia se faz por meio da própria "palavra" também. No que chamamos a "primeira parte" do poema, o nome aparece diversas vezes, grafado inteiro ou anagramaticamente. Já, na segunda parte, ocorre apenas duas vezes, representado pela sílaba "ly", sendo ao final reduzido a nada além da letra "l".

Na verdade, a presença desse "l”, e de alguns "pontos" vermelhos na segunda parte não permite falar em ausência e disjunção sujeito-objeto, pois, ainda que fragmentariamente, lygia está presente, o que nos leva a dizer que se trata de uma relação de "não-conjunção".

Ainda sobre o "l" final, vemos que pode ser mais um componente do bloco que constrói a isotopia da solidão, pois, visualmente, a letra "l" remete ao número um.

O quadro a seguir deve melhor sistematizar todas as relações que foram aqui mencionadas: 


\begin{tabular}{|c|c|c|c|}
\hline \multirow{4}{*}{ 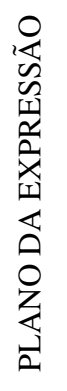 } & $\begin{array}{l}\text { Predominância de cores } \\
\text { quentes }\end{array}$ & $\begin{array}{l}\text { Predominância de cores } \\
\text { frias }\end{array}$ & \multirow{3}{*}{ Dimensão visual } \\
\hline & $\begin{array}{ll}\text { Cromatismo } & \text { mais } \\
\text { heterogêneo } & \end{array}$ & $\begin{array}{l}\text { Cromatismo mais } \\
\text { homogêneo }\end{array}$ & \\
\hline & Alto & Baixo & \\
\hline & $\begin{array}{l}\text { Anterioridade } \\
\text { /i// }\end{array}$ & $\begin{array}{l}\text { Posterioridade } \\
\text { /o/ }\end{array}$ & Dimensão sonora \\
\hline 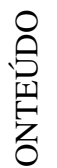 & $\begin{array}{l}\text { /Conjunção/ } \\
\text { "lynx" } \\
\text { "liame" } \\
\text { "com" }\end{array}$ & \multicolumn{2}{|l|}{$\begin{array}{l}\text { /Não-conjunção/ } \\
\text { "only" } \\
\text { "lonely" }\end{array}$} \\
\hline 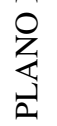 & $\begin{array}{l}\text { /euforia/ } \\
\text { "felix" }\end{array}$ & \multicolumn{2}{|l|}{$\begin{array}{l}\text { /disforia/ } \\
\text { "lacera" }\end{array}$} \\
\hline
\end{tabular}

Assim, vemos que nesse poema a relação entre expressão e conteúdo é totalmente significativa, e colabora para a organização do poema. As cores e a sonoridade, além de representar plástica e sonoramente "lygia", assumem a função de separar dois momentos distintos, e indicar a transformação de estado na relação sujeitoobjeto.

Dentre as muitas maneiras pelas quais "lygia fingers" pode ser lido, privilegiamos neste breve estudo as correlações internas entre conteúdos narrativos e categorias plásticas, tais como o cromatismo e a disposição topológica das palavras, sílabas, letras sobre o branco da página. Acreditamos ter dado, assim, um passo a mais rumo à compreensão e à avaliação da produção dos poetas concretos. 


\section{REFERÊNCIAS BIBLIOGRÁFICAS}

BERTRAND, Denis. Caminhos da semiótica literária. Trad. Grupo Casa. Bauru, SP: EDUSC, 2003.

CAMARA, Rogério. Grafo-sintaxe concreta: o projeto noigandres. Rio de Janeiro: Rios Ambiciosos, 2000.

CAMPOS, Augusto de. Viva Vaia (poesia 1949-1979). São Paulo: Ateliê Editorial, 2000.

FLOCH, Jean-Marie. Petites mythologies de l'œil et de l'esprit-pour une sémiotique plastique. Paris: Hades-Benjamins, 1995.

GREIMAS, Ensaios de Semiótica Poética. São Paulo: Cultrix, 1972.

STERZI, Eduardo. "Todos os sons, sem som". In: SUSSEKIND, Flora \& RODRIGUES, Julio C. Sobre Augusto de Campos. Rio de Janeiro: Fundação Casa Rui Barbosa, 2004. 
ANEXOS

1. o poema "lygia fingers"

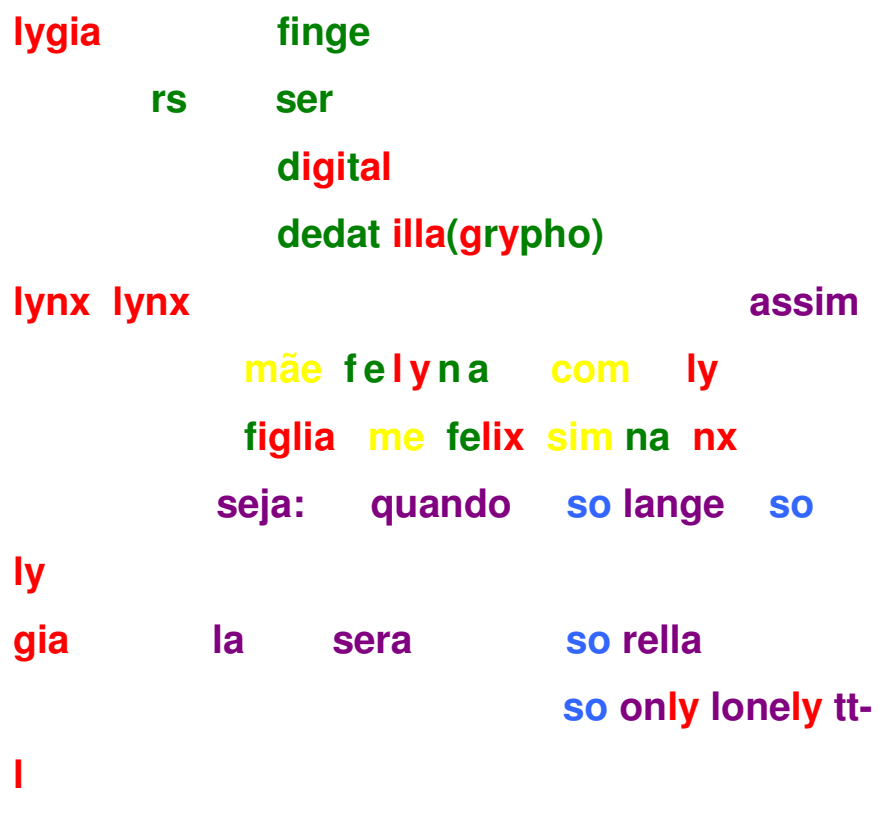


2. dimensão visual do poema, destaque para a cor vermelha

\begin{tabular}{|c|c|c|}
\hline lygia & $\begin{array}{l}\text { finge } \\
\text { ser } \\
\text { digital } \\
\text { dedat illa(gryp }\end{array}$ & ho) \\
\hline lynx Iynx & $\begin{array}{l}\text { mãe felyna } \\
\text { figlia me felix }\end{array}$ & $\begin{array}{l}\text { assim } \\
\text { com ly } \\
\text { sim na } n x\end{array}$ \\
\hline $\begin{array}{l}\text { ly } \\
\text { gia }\end{array}$ & $\begin{array}{l}\text { seja: quando } \\
\text { la sera }\end{array}$ & $\begin{array}{l}\text { so lange so } \\
\text { so rella } \\
\text { so only lonely tt- }\end{array}$ \\
\hline
\end{tabular}


3. dimensão sonora do poema, destaque para o fonema /i/

\begin{tabular}{|c|c|c|}
\hline Iygia & $\begin{array}{l}\text { finge } \\
\text { ser } \\
\text { digital } \\
\text { dedat illa(gryp }\end{array}$ & ho) \\
\hline Iynx Iynx & $\begin{array}{l}\text { mãe felyna } \\
\text { figlia me felix }\end{array}$ & $\begin{array}{l}\text { assim } \\
\text { com ly } \\
\text { sim na } n x\end{array}$ \\
\hline $\begin{array}{l}\text { ly } \\
\text { gia }\end{array}$ & $\begin{array}{l}\text { seja: quando } \\
\text { la sera }\end{array}$ & $\begin{array}{l}\text { so lange so } \\
\text { so rella } \\
\text { so only lonely tt- }\end{array}$ \\
\hline
\end{tabular}

\section{Como citar este artigo:}

PONDIAN, Juliana Di Fiori. Relações entre expressão e conteúdo na poesia concreta. Estudos Semióticos, Número 1, São Paulo, 2005.

Disponível em <www.fflch.usp.br/dl/semiotica/es $>$. Acesso em

"dia/mês/ano". 